\title{
Elucidating the Awareness of Dental Doctors in Following Dental Protocol by M.O.H about the COVID-19 Pandemic in KSA
}

Dr. Aisha Zakaria Hashem Mostafa ${ }^{*}$, Fatimah Saud AlShammari, Motieah Hathal AlShammari, Nada Nasser AlMansour, Beshaeir Klaeif Albalwi, Lamia Nafea AlShammari, Malak Farraj Altwalah, Fatima Sultana

Department of Dentistry, Hail University, Hail, Saudi Arabia

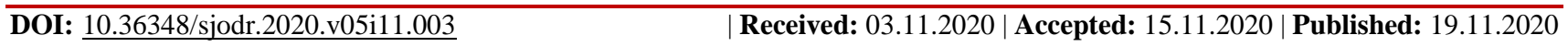

*Corresponding author: Dr. Aisha Zakaria Hashem Mostaf

\section{Abstract}

The causative organism for the COVID-19 is severe acute respiratory syndrome coronavirus 2 (SARS-CoV-2) virus. The common symptoms of the COVID-19 are: fever, dry cough and fatigue while the less common symptoms are: aches and pain, sore throat, diarrhoea, conjunctivitis, headache, loss of taste and smell, rash on skin, and discolouration of fingers and toes. Several studies reported that person of any age can be infected by the virus, but elderly patients with systemic diseases were more vulnerable to the virus. According to the World Health Organization (WHO), dentistry is the profession with high mode of exposure to the Covid-19 virus. The statistics as recorded on $20^{\text {th }}$ October, 2020 shows that there are a total of 342,968 confirmed cases of COVID-19 in Saudi Arabia, with 5,217 deaths and 329,270 recovered cases. The Ministry of Health $(\mathrm{MOH})$ of Saudi Arabia proposed a dental emergency protocol during the COVID-19 pandemic on $13^{\text {th }}$ April, 2020. This dental emergency protocol guides the triage, assessment and provision of the emergency dental treatment during the current COVID-19 pandemic. The dental care was divided into 4 by the Ministry of Health in Saudi Arabia in this dental emergency protocol as: Emergent dental care, urgent dental care, non-urgent dental care and Advice and self-care. The main aim of this study is to assess the awareness of dental doctors in following dental protocol by M.O.H about the covid-19 in Kingdom of Saudi Arabia. A pre-designed questionnaire is circulated online using Google form to record the results of the survey of elucidating the awareness of dental doctors in following dental protocol by M.O.H about the covid-19 in Saudi Arabia. The data that is collected from the questionnaire is analysed using the computer software Statistical package for social sciences that is SPSS 16. The protocol included all the information about the type of orofacial problem and the recommended management related to it. Nearly about 70 to 80 percent of the dental doctors that participated in this survey are aware about all the guidelines provided by the Ministry of Health. Every dental doctor practising in the Kingdom of Saudi Arabia is to be made aware of all the guidelines and protocol to be followed during the emergency dental care.

Keywords: COVID-19, dental care, MOH protocol, dental doctors, Saudi Arabia.

Copyright (C) 2020 The Author(s): This is an open-access article distributed under the terms of the Creative Commons Attribution 4.0 International License (CC BY-NC 4.0) which permits unrestricted use, distribution, and reproduction in any medium for non-commercial use provided the original author and source are credited.

\section{INTRODUCTION}

Coronavirus disease 19 , commonly referred as COVID-19 that stands for CO-corona, V-virus, Iinfectious, D-disease, 19-spread in the year 2019 [1]. Like the Severe Acute Respiratory Syndrome (SARS COV), the COVID-19 has the same host receptor that is human angiotensin converting enzyme 2 (ACE-2). COVID-19 was first discovered in the city of Wuhan, China in December 2019. Later the virus spreads globally that resulted the World Health Organization to declare it as 2019-2020 pandemic [2]. This virus has an incubation period of about 2 to 12 days, some of the studies also reported an incubation period of 24 days. The common symptoms of the COVID-19 are high fever, shortness of breath, dry cough, fatigue and tiredness. Among all the cases reported, $15 \%$ were marked as severely ill and $5 \%$ as critically ill, and the remaining $80 \%$ were mildly ill and recovered without any special therapy [3]. The COVID-19 can even lead to pneumonia, kidney failure and can even cause death. For the severely ill and critically ill patients, a special oxygen therapy and intensive care is needed. The transfer of the virus from the infected humans to other humans was via. Saliva and nasal droplets, direct or indirect contact and even through the stools of the infected person. The transmission via. Aerosols, formites and asymptomatic carriers was also reported in several studies.The respiratory droplets can remain active in the air for 3 to 4 hours and for many days on the surfaces contaminated by the COVID-19 virus [4]. 
Several studies reported that person of any age can be infected by the virus, but elderly patients with systemic diseases were more vulnerable to the virus.

An alteration to the dental therapy is needed in this pandemic to avoid the transmission of the virus between the patients and the dental team [5]. In the dental practice, the frequent use of surgical and rotary tools can create micro droplets of the saliva, water, blood, microbes and dental debris in the air. This can act as a mode of transmission of the virus from both the symptomatic or the asymptomatic COVID-19 patients to the dental staff or the healthy patient. According to the World Health Organization (WHO), dentistry is the profession with high mode of exposure to the Covid-19 virus [2]. A protocol or guidelines were to be set for the dental department to reduce the transfer of the virus. In order to minimise the new infections and the progressive mode of virus transfer, the use of personal protective equipment (PPE) and the disinfectants is crucial [6]. The personal protection is essential for both the dental team and the patients due to the high proliferation of the virus. Several surfaces made up of different materials helps the survival of the virus in it for different days, like paper and copper allow the virus to survive on it for 2 to 24 hours while plastics allows the survival for 72 hours and steel for 48 hours. Therefore all the places in the dental clinic should be considered as the risks for the transmission of the virus [7].

The dental protocol for the COVID-19 pandemic must include the screening and consideration of the asymptomatic patients up to 30 days of recovery from the virus, consideration of every patient as the asymptomatic carrier of the virus. Consideration of only the urgent and the emergency cases for the treatment in the dental clinic and counselling the non emergency cases over the phone. Utilisation of all preventive measures that can be taken to minimize the transfer of the virus. All the medical and travel history of the patient to be taken into consideration before the appointment.

The statistics as recorded on $20^{\text {th }}$ October, 2020 shows that there are a total of 342,968 confirmed cases of COVID-19 in Saudi Arabia, with 5,217 deaths and 329,270 recovered cases. The Ministry of Health $(\mathrm{MOH})$ of Saudi Arabia proposed a dental emergency protocol during the COVID-19 pandemic on $13^{\text {th }}$ April, $2020[8,9]$. This dental emergency protocol guides the triage, assessment and provision of the emergency dental treatment during the current COVID-19 pandemic. The protocol targets the dentist, hygienist, dental assistants and dental technicians that work in the dental care. The dental emergency protocol assists in the management of the emergency dental cases during the COVID-19 pandemic; it identifies the challenges for the dental care provision, to provide and implement the prevention control guideline and to deliver a quality control during the COVID-19 outbreak [10]. The general considerations that were made by the Ministry of Health in this protocol was to treat urgent/emergency children or adults cases, to postpone the routine dental check-ups of the patients, all the demographic and health factors need to be considered during the dental procedures, during the assessment of the patients the safety of the dental staff and the patient should be given utmost importance, to encourage the non-urgent cases to maintain good oral hygiene and consuming healthy diet [12].

The dental care was divided into 4 by the Ministry of Health in Saudi Arabia in this dental emergency protocol as: Emergent dental care, urgent dental care, non-urgent dental care and Advice and selfcare. All the potential life threatening conditions were considered in the emergent dental care that includes uncontrolled bleeding, cellulitis, swelling of face, orofacial trauma [8, 9]. The severe and uncontrolled symptoms that cannot be treated by the patient and needs special attention of the dentist are included under the urgent dental care. The routine check-up of the patient and the elective dental procedures are all included in the non-urgent dental care, mild and moderate symptoms that can be managed by the patient via dentist advice using analgesics and antibiotics are all included in the advice an self-care. Thorough knowledge about the protocol is essential by the dental doctors and hence we chose to survey the dental doctors about their knowledge and awareness about the dental emergency protocol. With the present study we can elucidate the awareness of the dental doctors about the dental awareness protocol by the $\mathrm{MOH}$ during the COVID-19 pandemic $[8,9]$.

\section{AIM AND OBJECTIVES}

The main aim of this study is to assess the awareness of dental doctors in following dental protocol by M.O.H about the covid-19 in Kingdom of Saudi Arabia.

\section{Specific Objectives}

- Carrying out a survey to evaluate the awareness of the dental doctors practising in Saudi Arabia about COVID-19 protocol.

- Determining the attitude of the dental doctors regarding the working guidelines and protocol to be followed while working in the dental clinic.

\section{METHODOLOGY}

A pre-designed questionnaire is circulated online using Google form to record the results of the survey of elucidating the awareness of dental doctors in following dental protocol by M.O.H about the covid-19 in Saudi Arabia. This study is conducted in the year 2020. The questionnaire is designed in English language and later is translated into Arabic language. 
The questionnaire includes the questions related to the demographic data of the dental doctors followed by questions related to Awareness about COVID-19 and dentistry.

\section{DATA COLLECTION}

The results of the questionnaire survey of elucidating the awareness of dental doctors in following dental protocol by M.O.H about the covid-19 in Saudi Arabia is recorded. The result of the survey is analysed using the SPSS software. The frequencies and percentage of the results of elucidating the awareness of dental doctors in following dental protocol by M.O.H about the covid-19 in Saudi Arabia is done using the $\mathrm{P}$ value less than or equal to 0.05 .

\section{Data Management and Analysis Plan}

The data that is collected from the questionnaire is analysed using the computer software Statistical package for social sciences that is SPSS 16. The frequencies and percentages of the responses from the adult population in Saudi Arabia is done using the $\mathrm{P}$ value equal to or less than 0.05 . The descriptive statistics is attained and the mean, standard deviation and frequency distribution is calculated. Data is stored in a password-protected computer in a database created by the PI working on this project. A hard copy of the data and Identification variable is maintained in a locked file cabinet in the research coordinator office. Only those involved in the study have access to data. All data is identified. Data is retained indefinitely.

\section{RESULTS}

The elucidation of awareness of dental doctors following the dental protocol issued by Ministry Of Health about the COVID-19 pandemic in Kingdom of Saudi Arabia was done using a questionnaire about the socio-demographic characters like age, gender, experience, working sector, etc.

\section{Demographic Characters}

About $42(45.7 \%)$ of the dental doctors are in the age group more than 30 years, $33(35.9 \%)$ were in the age group 26-30 years, $16(17.4 \%)$ are in the age group 21-25 years and $1(1.1 \%)$ are in the age groups 19-20 years. Majority of the participants, 63 (69.2\%) were males and $28(30.8 \%)$ were females. Around 27 $(30.3 \%)$ had only 1 year of experience, $26(29.2 \%)$ of the participants had more than 10 years, $13(14.6 \%)$ had 2 years of experience, $9(10.1 \%)$ had about $5-10$ years of experience, $7(7.9 \%)$ of the dental doctors had 3 years of working experience, $4(4.5 \%)$ participants had 4 years of experience whereas $3(3.4 \%)$ dental doctors had about 5 years of experience.

\begin{tabular}{|l|l|l|}
\hline DEMOGRAPHIC CHARACTERS & FREQUENCY & PERCENTAGE \\
\hline Age & 1 & \\
19 - 20 years & 16 & 1.1 \\
21 - 25 years & 33 & 17.4 \\
26 - 30 years & 42 & 35.9 \\
>30 years & & 45.7 \\
\hline Gender & 28 & \\
Female & 63 & 30.8 \\
Male & & 69.2 \\
\hline Experience & 27 & \\
1 year & 13 & 30.3 \\
2 year & 7 & 14.6 \\
3 year & 4 & 7.9 \\
4 year & 3 & 4.5 \\
5 year & 9 & 3.4 \\
5-10 year & 26 & 10.1 \\
More than 10 year & 32 & 29.2 \\
\hline Working & \\
In Private sector & 32 & 37.6 \\
In Public sector & 40 & 47.1 \\
Is Unemployed & 13 & 15.3 \\
\hline Nationality & & \\
Saudi & 85 & 92.4 \\
Non-Saudi & 7 & 7.6 \\
\hline
\end{tabular}

The majority of the dental doctors work in a public sector, about $40(47.1 \%) ; 32(37.6 \%)$ work in the private sector and $13(15.3 \%)$ were unemployed. 85 $(92.4 \%)$ were Saudi nationals and $7(7.6 \%)$ of the dental doctors were Non-Saudi residents. Below is the graphical representation of Gender, working sectors, working experience and nationality of the dental doctor participants. 


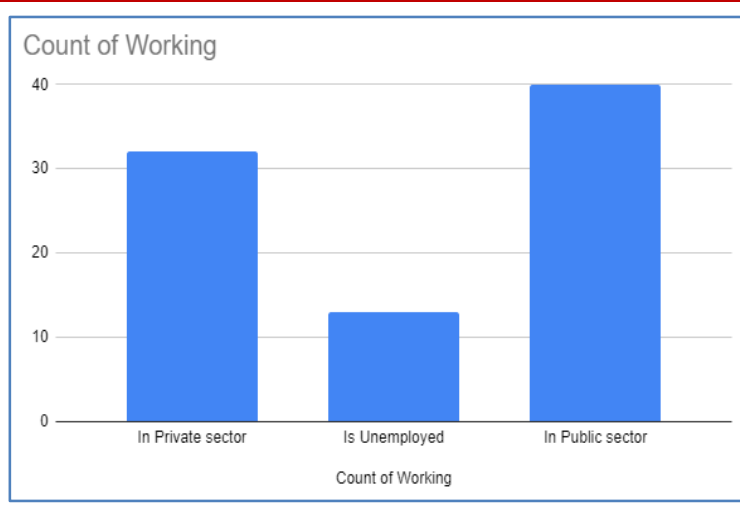

Graphical representation of Working Sector of the Dental Doctors

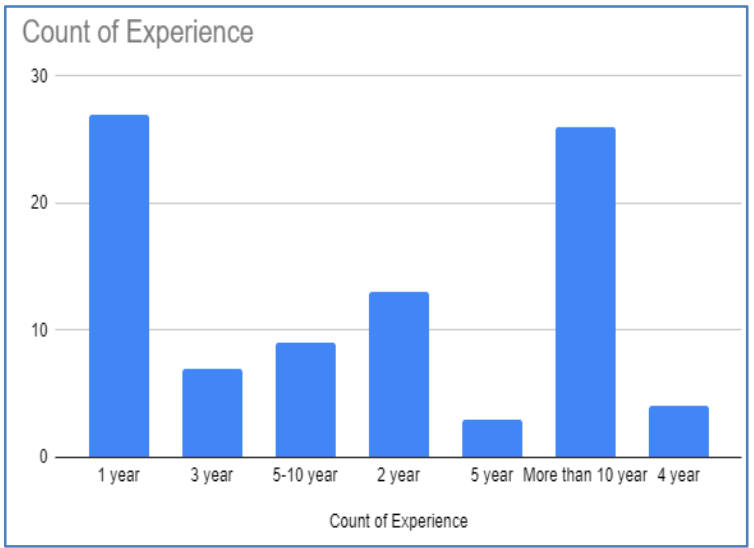

Graphical representation of Working Experience of the Dental Doctors

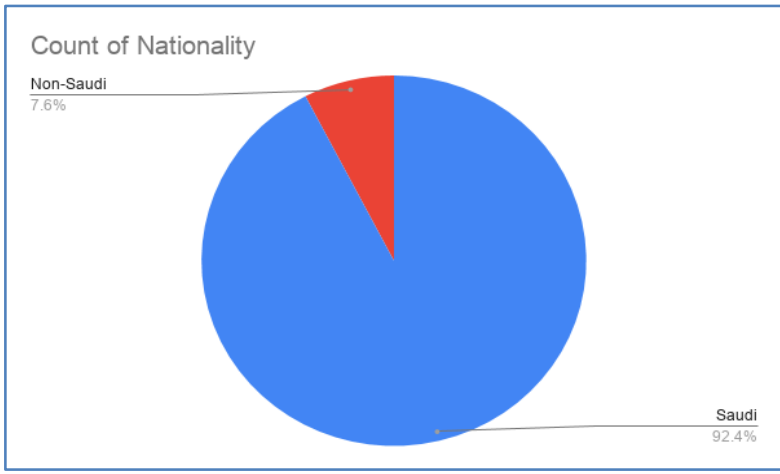

Pie-Diagram representing the nationality of dental doctors

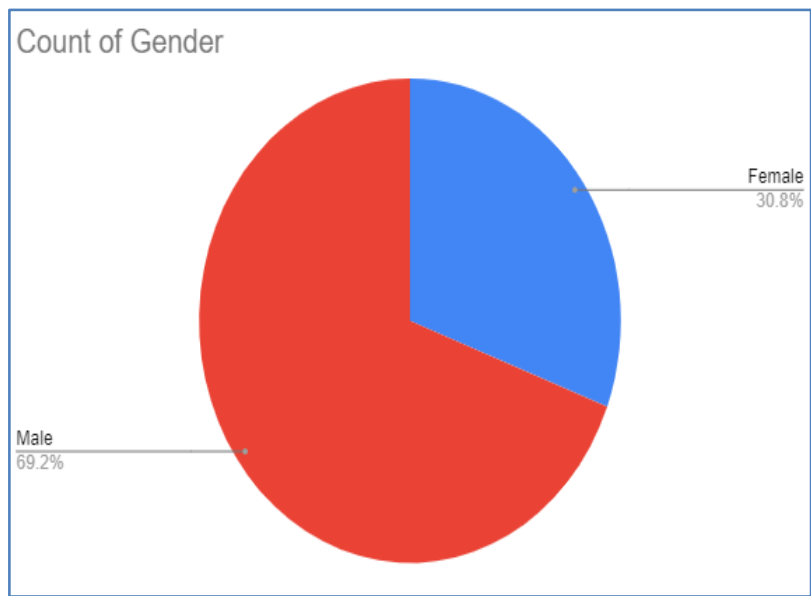

Pie-Diagram representing the Gender of dental doctors

\begin{tabular}{|c|c|c|c|}
\hline AWARENESS ABOUT COVID 19 IN DENTAL SERVICES & YES (\%) & NO $(\%)$ & P-Value \\
\hline $\begin{array}{l}\text { Are you aware that the dental services are limited to emergency care according to the ministry } \\
\text { of Health, in Saudi Arabia? }\end{array}$ & $\begin{array}{l}79 \\
(85.9 \%) \\
\end{array}$ & $\begin{array}{l}13 \\
(14.1 \%)\end{array}$ & 0.014 \\
\hline $\begin{array}{l}\text { Are you aware of the guidelines by MOH to be followed by dentists, hygienists, dental } \\
\text { assistants, and dental technicians working in the dental department? }\end{array}$ & $\begin{array}{l}74 \\
(80.4 \%) \\
\end{array}$ & $\begin{array}{l}18 \\
(19.6 \%)\end{array}$ & 0.021 \\
\hline $\begin{array}{l}\text { Are you aware of the protocol released by MOH helps to identify the challenges that the } \\
\text { COVID-19 epidemic presents for the provision of dental care? }\end{array}$ & $\begin{array}{l}66 \\
(71.7 \%)\end{array}$ & $\begin{array}{l}26 \\
(28.3 \%)\end{array}$ & 0.027 \\
\hline $\begin{array}{l}\text { Are you aware that the protocol helps to provide and implement Infection Prevention } \\
\text { and Control guidance during the management of dental emergency cases during COVID } 19 \\
\text { outbreak? }\end{array}$ & $\begin{array}{l}73 \\
(78.5 \%)\end{array}$ & $\begin{array}{l}20 \\
(21.5 \%)\end{array}$ & 0.020 \\
\hline $\begin{array}{l}\text { Are you aware that the emergency dental care includes uncontrolled bleeding, significant } \\
\text { infection, facial swelling and oral facial trauma potentially compromising the patient's } \\
\text { airway? }\end{array}$ & $\begin{array}{l}64 \\
(68.8 \%)\end{array}$ & $\begin{array}{l}29 \\
(31.2 \%)\end{array}$ & 0.030 \\
\hline $\begin{array}{l}\text { Are you aware that the mild and moderate symptoms of dental pain and dental infections can } \\
\text { be treated by prescribing the analgesics and antimicrobials to the patient? }\end{array}$ & $\begin{array}{l}79 \\
(85.9 \%)\end{array}$ & $\begin{array}{l}13 \\
(14.1 \%)\end{array}$ & 0.014 \\
\hline $\begin{array}{l}\text { Are you aware that the dental protocol of COVID-19 suggests that Dentists should } \\
\text { follow a strict infection control protocol guide with all the emergency dental patients? }\end{array}$ & $\begin{array}{l}75 \\
(81.5 \%) \\
\end{array}$ & $\begin{array}{l}17 \\
(18.5 \%)\end{array}$ & 0.022 \\
\hline $\begin{array}{l}\text { Are you aware of maintaining hand hygiene in the dental clinic to avoid the transmission } \\
\text { of covid-19 infection between the patient and the dental doctor? }\end{array}$ & $\begin{array}{l}83 \\
(89.2 \%)\end{array}$ & $\begin{array}{l}10 \\
(10.8 \%)\end{array}$ & 0.009 \\
\hline $\begin{array}{l}\text { Are you aware that the direct contact should be avoided of the eyes, nose and mouth of the } \\
\text { dental doctor to avoid the transfer of infection? }\end{array}$ & $\begin{array}{l}79 \\
(84.9 \%)\end{array}$ & $\begin{array}{l}14 \\
(15.1 \%)\end{array}$ & 0.014 \\
\hline $\begin{array}{l}\text { Are you aware that the doctor should use the precautionary measures like surgical face masks, } \\
\text { protective eye wear, Gloves, Head covers, eye protection, N95-or higher respirator } 95 \text { ? }\end{array}$ & $\begin{array}{l}83 \\
(89.2 \%) \\
\end{array}$ & $\begin{array}{l}10 \\
(10.8 \%) \\
\end{array}$ & 0.009 \\
\hline $\begin{array}{l}\text { Are you aware that panoramic radio-graph should be used to diagnose the problem in the } \\
\text { dental clinic? }\end{array}$ & $\begin{array}{l}70 \\
(75.3 \%)\end{array}$ & $\begin{array}{l}23 \\
(24.7 \%)\end{array}$ & 0.018 \\
\hline Are you aware that CBCT can also be used in the dental clinic for diagnosis? & $\begin{array}{l}61 \\
(65.6 \%)\end{array}$ & $\begin{array}{l}32 \\
(34.4 \%)\end{array}$ & 0.034 \\
\hline Are you aware that Occlusal radio-graphs may need to be used for diagnosis? & $\begin{array}{l}57 \\
(62 \%)\end{array}$ & $\begin{array}{l}35 \\
(38 \%)\end{array}$ & 0.045 \\
\hline
\end{tabular}


$79(85.9 \%)$ of the dental doctors are aware of the limitation of dental services only to dental emergency care by the ministry of health in Saudi Arabia; 13 (14.1\%) showed no awareness about it. 74 $(80.4 \%)$ of the dental doctors are aware about the guidelines guidelines by $\mathrm{MOH}$ to be followed by dentists, hygienists, ental assistants, and dental technicians working in the dental department; while 18 $(19.6 \%)$ are not aware of this. $66(71.7 \%)$ are aware of the protocol released by $\mathrm{MOH}$ helps to identify the challenges that the COVID-19 epidemic presents for the provision of dental care, while $26(28.3 \%)$ are not aware of this. $73(78.5 \%)$ are aware that the protocol helps to provide and implement Infection Prevention and Control guidance during the management of dental emergency cases during COVID 19 outbreak; while 20 $(21.05 \%)$ are not aware about this. $64(68.8 \%)$ are aware that the emergency dental care includes uncontrolled bleeding, significant infection, facial swelling and oral facial trauma potentially compromising the patient's airway; while 29 (31.2\%) are not aware about it. $79(85.9 \%)$ are aware that the mild and moderate symptoms of dental pain and dental infections can be treated by prescribing the analgesics and antimicrobials to the patient; whereas $13(14.1 \%)$ shows no awareness about this. $83(89.2 \%)$ are aware that the mild and moderate symptoms of dental pain and dental infections can be treated by prescribing the analgesics and antimicrobials to the patient; while 10 $(10.8 \%)$ are not aware about it. $79(84.9 \%)$ are aware that the direct contact should be avoided of the eyes, nose and mouth of the dental doctor to avoid the transfer of infection; whereas $14(15.1 \%)$ are not aware. $83(89.2 \%)$ are aware that the doctor should use the precautionary measures like surgical face masks, protective eye wear, Gloves, Head covers, eye protection, N95-or higher respirator 95; while 10 $(10.8 \%)$ are not aware about this. $70(75.3 \%)$ are aware that panoramic radio-graph should be used to diagnose the problem in the dental clinic; whereas $23(24.7 \%)$ shows no awareness. $61(65.6 \%)$ are aware that CBCT can also be used in the dental clinic for diagnosis; 32 $(34.4 \%)$ are not aware regarding this. $57(62 \%)$ are aware that Occlusal radio-graphs may need to be used for diagnosis and $35(38 \%)$ are not aware about it. Based on the present survey we can say that majority of the dental doctors are well aware about the protocol to be followed by them during this COVID-19 pandemic in the emergency dental care unit. The P-value was significantly found to be less than 0.05 .

\section{DISCUSSION}

The COVID-19 pandemic was declared by the World Health Organization (WHO) as a public health emergency. The COVID-19 was seen for the first time in the city of Wuhan, in China [2]. The physical appearance of the virus structure resembled a crown and was identified as coronavirus. The statistics as recorded on $20^{\text {th }}$ October, 2020 shows that there are a total of 342,968 confirmed cases of COVID-19 in Saudi Arabia, with 5,217 deaths and 329,270 recovered cases. The Ministry of Health (MOH) of Saudi Arabia proposed a dental emergency protocol during the COVID-19 pandemic on $13^{\text {th }}$ April, 2020. The current study was done to make awareness among all the dental doctors of Saudi Arabia about the protocol issued by the Ministry of Health regarding the emergency dental care. The awareness can help to minimize the spread of the deadly virus in the dental care department. The protocol included all the information about the type of orofacial problem and the recommended management related to it. The recommended management was categorized into advice and self-help, urgent care and emergency care segments. This help in carrying out the procedures in an easy way with minimum exposure with the coronavirus.

Various orofacial problems that were included in the protocol were: acute apical abscess, acute periodontal abscess. Perio-endo lesions, acute pericoronitis, dry socket, irreversible pulpitis, reversible pulpitis, dentine hypersensitivity, suture removal, oral ulcer, post extraction haemorrhage, uncontrolled bleeding in orofacial region, fracture or loose tooth fragments or restorations (tooth-crown bridge), dentoalveolar trauma, ill-fitting or loose denture, trauma from wire digging, broken bonded retainers, temporomandibular joint arthralgia and/or myalgia.

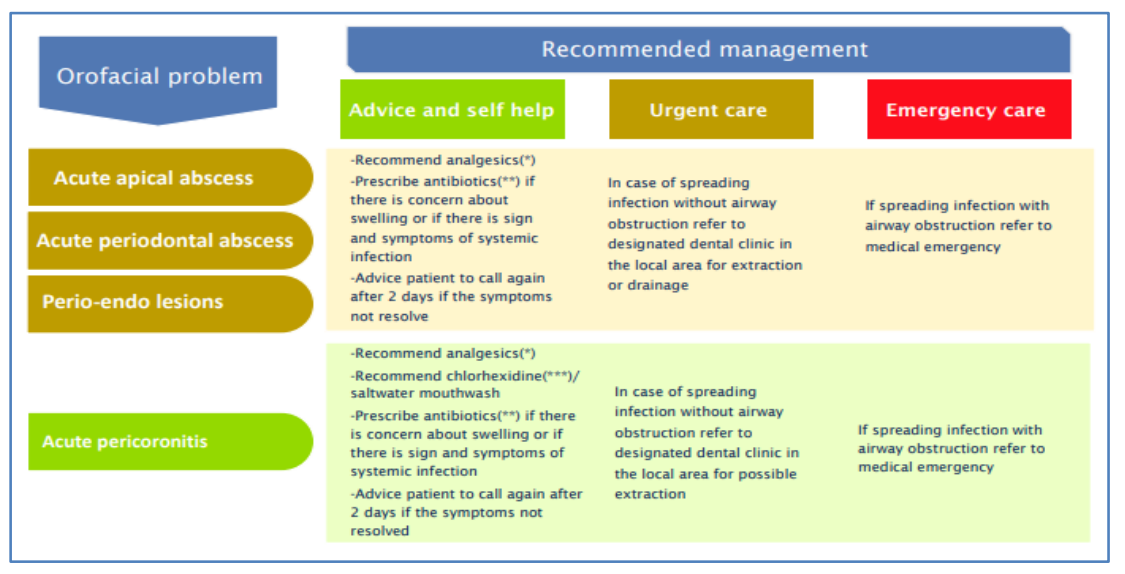


Aisha Zakaria Hashem Mostafa et al., Saudi J Oral Dent Res, Nov, 2020; 5(11): 538-545
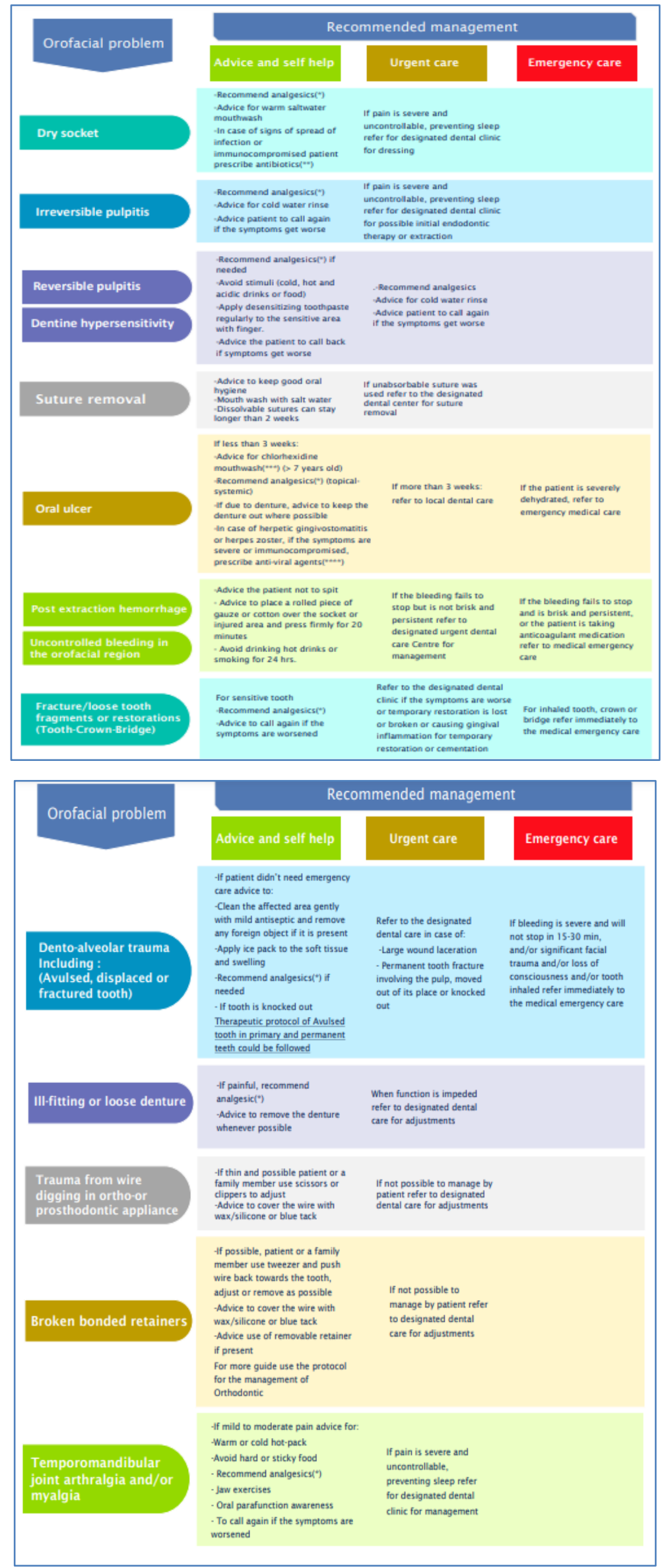
Proper awareness is to be given to the dental doctors to follow tele-dentistry successfully in treating their patients with various oral health care problems causing minimum spread of the coronavirus [13-15]. Apart from using personal protective equipment, the work flow patterns and the layouts of the dental clinics need to be changed in-order to reduce the direct exposure of the dentist and other staff with their patients [16-20]. The following are the personal protective measures to be taken by the dentist while treating the patient according to the World Health Organization (WHO) [21].

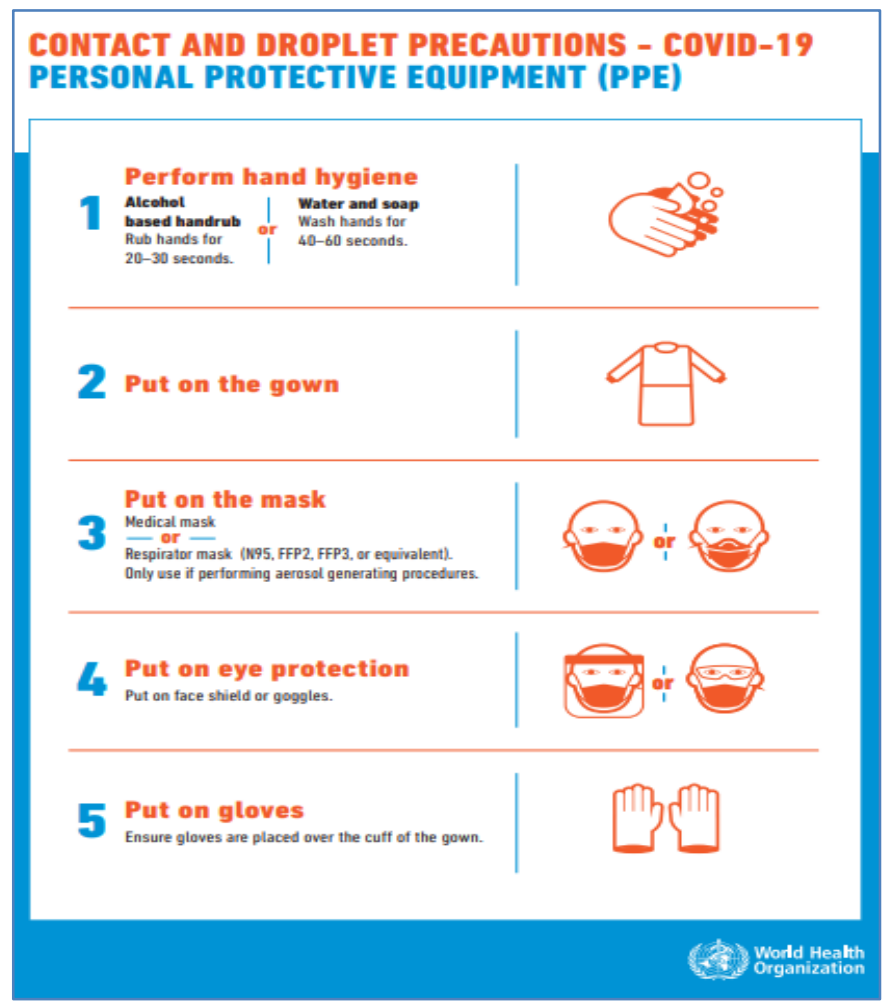

The aerosol generation during the dental therapy need to be minimized by developing new and innovative techniques. The entire layout of the dental department need to be re-organized for this pandemic situation and its procedure is given in the protocol by the Ministry of Health. Proper cleaning and sanitization techniques to be used before and after the treatment of every patient. A bulk supply of face mask and hand sanitizer need to be made available for all the patients visiting the dental clinic. The air filtration devices need to be installed in the dental clinics to purify the air [22]. Every patient visiting the dental clinic need to be considered as a carrier of the coronavirus and proper preventive measures need to be taken?

\section{CONCLUSION}

Nearly about 70 to 80 percent of the dental doctors that participated in this survey are aware about all the guidelines provided by the Ministry of Health. Every dental doctor practising in the Kingdom of Saudi Arabia is to be made aware of all the guidelines and protocol to be followed during the emergency dental care. As it's a pandemic for the year 2019-2020, very less literature is available about the COVID-19 and its virus. More surveys need to be done including all the dental care takers in Saudi Arabia to estimate more clear results.

\section{ACKNOWLEDGEMENT}

We would like to thank all the dental doctors of Saudi Arabia who participated in this survey and also for their time and co-operation.

\section{Ethical considerations \\ Compliance with ethical standards}

Ethical approval: This proposal contains survey studies with human participants that are the dental doctors practising in Saudi Arabia performed by any of the authors.

Conflict of interest: The authors do not have any commercial associations that might pose or create a conflict of interest with information presented in this communication. No intramural or extramural funding supported any aspect of this work.

\section{REFERENCES}

1. Kochhar, A. S., Bhasin, R., Kochhar, G. K., \& Dadlani, H. (2020). Provision of Continuous Dental Care for Oral Oncology Patients during \& after COVID-19 Pandemic. Oral Oncology. 
2. Coronavirus disease (COVID-19) outbreak situation: WHO,"

2020, https://www.who.int/emergencies/diseases/n ovel-coronavirus-2019.

3. Suri, S., Vandersluis, Y. R., Kochhar, A. S., Bhasin, R., \& Abdallah, M. N. (2020). Clinical orthodontic management during the COVID-19 pandemic. The Angle Orthodontist.

4. Fini, M. B. (2020). What dentists need to know about COVID-19. Oral Oncology, 104741.

5. Riou, J., \& Althaus, C. L. (2020). Pattern of early human-to-human transmission of Wuhan 2019 novel coronavirus (2019-nCoV), December 2019 to January 2020. Eurosurveillance, 25(4), 2000058.

6. Kam, K. Q., Yung, C. F., Cui, L., Tzer Pin Lin, R., Mak, T. M., Maiwald, M., ... \& Thoon, K. C. (2020). A well infant with coronavirus disease 2019 with high viral load. Clinical Infectious Diseases.

7. Lo Giudice, R. (2020). The Severe Acute Respiratory Syndrome Coronavirus-2 (SARS CoV2) in Dentistry. Management of Biological Risk in Dental Practice. International Journal of Environmental Research and Public Health, 17(9), 3067.

8. $\mathrm{MOH}$ guideline for dental care (2020).

https://www.moh.gov.sa/Ministry/MediaCenter/Pu blications/Documents/MOH-Guidelines-for-reopening-June-.pdf

9. MOH, \& Weqaya. (2020). Coronavirus Disease 19 (COVID-19) Guidelines. Retrieved from https://www.moh.gov.sa/CCC/healthp/regulations/ Documents/Coronav irus\%20Disease\%202019\%20Guidelines\%20v1.1.. pdf

10. Chan, J. F. W., Yuan, S., Kok, K. H., To, K. K. W., Chu, H., Yang, J., ... \& Tsoi, H. W. (2020). A familial cluster of pneumonia associated with the 2019 novel coronavirus indicating person-to-person transmission: a study of a family cluster. The Lancet, 395(10223), 514-523.

11. Yang, J., Zheng, Y., Gou, X., Pu, K., Chen, Z., Guo, Q., ... \& Zhou, Y. (2020). Prevalence of comorbidities in the novel Wuhan coronavirus (COVID-19) infection: a systematic review and meta-analysis. International journal of infectious diseases.

12. Spagnuolo, G., De Vito, D., Rengo, S., \& Tatullo, M. (2020). COVID-19 outbreak: An overview on dentistry.

13. Klompas, M. (2020). Coronavirus disease 2019 (COVID-19): protecting hospitals from the invisible.

14. Lu, C. W., Liu, X. F., \& Jia, Z. F. (2020). 2019 nCoV transmission through the ocular surface must not be ignored. Lancet (London, England), 395(10224), e39.

15. Centers for Disease Control and Prevention. (2020). Centers for Disease Control and Prevention Coronavirus disease 2019 (COVID-19) 2020.

16. Carrouel, F., Conte, M. P., Fisher, J., Gonçalves, L. S., Dussart, C., Llodra, J. C., \& Bourgeois, D. (2020). COVID-19: A recommendation to examine the effect of mouthrinses with $\beta$-cyclodextrin combined with citrox in preventing infection and progression.

17. Meng, L., Hua, F., \& Bian, Z. (2020). Coronavirus disease 2019 (COVID-19): emerging and future challenges for dental and oral medicine. Journal of Dental Research, 99(5), 481-487.

18. Center for Disease Control and Prevention, "Dental settings. (2020).'

2020, https://www.cdc.gov/coronavirus/2019ncov/hcp/dental-settings.html.

19. Ather, A., Patel, B., Ruparel, N. B., Diogenes, A., \& Hargreaves, K. M. (2020). Coronavirus disease 19 (COVID-19): implications for clinical dental care. Journal of endodontics.

20. Wang, P., Anderson, N., Pan, Y., Poon, L., Charlton, C., Zelyas, N., \& Babcock, H. (2020). The SARS-CoV-2 outbreak: diagnosis, infection prevention, and public perception. Clinical Chemistry, 66(5), 644-651.

21. https://www.who.int/csr/resources/publications/Co ntact-Droplet-COVID-19-Precautions.pdf?ua=1

22. General Directorate of Infection Prevention and Control (GDIPC), M. (March-2020). Guidance for the Proper Selection and Use of Personal Protective Equipment (PPE) in Healthcare Settings. 